The INL is a

U.S. Department of Energy

National Laboratory

operated by

Battelle Energy Alliance

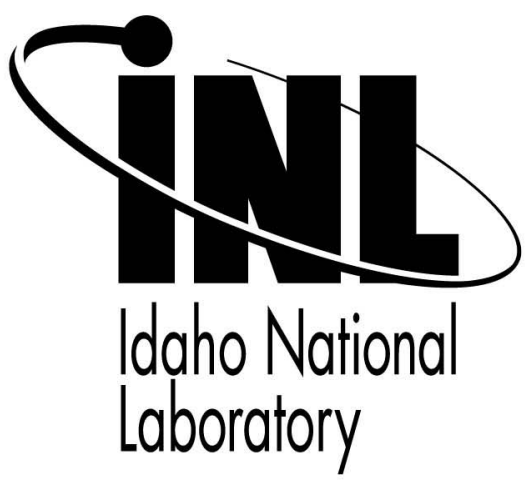

\title{
Engineering-Scale Liquid Cadmium Cathode Experiments
}

\section{International Pyroprocessing Research Conference}

\author{
D. Vaden
}

S. X. Li

B. R. Westphal

K. B. Davies

T. A. Johnson

D. M. Pace

\section{August 2006}

This is a preprint of a paper intended for publication in a journal or proceedings. Since changes may be made before publication, this preprint should not be cited or reproduced without permission of the author. This document was prepared as an account of work sponsored by an agency of the United States Government. Neither the United States Government nor any agency thereof, or any of their employees, makes any warranty, expressed or implied, or assumes any legal liability or responsibility for any third party's use, or the results of such use, of any information, apparatus, product or process disclosed in this report, or represents that its use by such third party would not infringe privately owned rights. The views expressed in this paper are not necessarily those of the United States Government or the sponsoring agency. 


\section{ENGINEERING-SCALE LIQUID CADMIUM CATHODE EXPERIMENTS}

\author{
D. VADEN,* S. X. LI, B. R. WESTPHAL, and K. B. DAVIES \\ Idaho National Laboratory, Pyroprocessing Technology, Idaho Falls, Idaho 83415
}

T. A. JOHNSON Idaho National Laboratory

Nuclear Facility Engineering Support, Idaho Falls, Idaho 83415

D. M. PACE Idaho National Laboratory

Human Factors and I\&C Systems, Idaho Falls, Idaho 83415

Recovery of uranium and transuranic (TRU) actinides from spent nuclear fuel by an electrorefining process was investigated as part of the U.S. Department of Energy Advanced Fuel Cycle Initiative. Experiments were performed in a shielded hot cell at the Materials and Fuels Complex at Idaho National Laboratory. The goal of these experiments was to collect, by an electrochemical process, kilogram quantities of uranium and plutonium into what is called a liquid cadmium cathode ( $L C C)$.

For each experiment, a steel basket loaded with chopped spent nuclear fuel from the Experimental Breeder Reactor II acted as the anode in the electrorefiner. The cathode was a beryllium oxide crucible containing $\sim 26 \mathrm{~kg}$ of cadmium metal (the LCC). In the three experiments performed to date, between 1 and $2 \mathrm{~kg}$ of heavy metal was collected in the LCC after passing an integrated current between 1.80 and 2.16 MC (500 and $600 \mathrm{Ah}$ ) from the anode to the cathode. Sample analysis of the processed LCC ingots measured detectable amounts of TRUs and rare earth elements.

\section{INTRODUCTION}

Electrorefining to recover transuranic (TRU) actinides from spent nuclear fuel is being investigated as part of the U.S. Department of Energy Advanced Fuel Cycle Initiative. This initiative supports the development of methods to (a) process spent fuel, (b) recycle valuable

*E-mail: dee.vaden@inl.gov fuel components, (c) provide proliferation resistance, and (d) occupy less repository space. The electrorefining process meets these objectives by dissolving spent fuel electrochemically, taking advantage of the different chemical and electrochemical properties of metals oxidizing to metal chlorides to separate uranium metal from the other components in spent nuclear fuel. ${ }^{1}$ Electrochemical transport occurs in a vessel called the electrorefiner. The electrorefiner contains a molten salt of $\mathrm{LiCl}-\mathrm{KCl}$ eutectic with dissolved metal chlorides such as $\mathrm{UCl}_{3}$ and $\mathrm{PuCl}_{3}$ as the electrolyte. Steel baskets containing chopped spent fuel (segments) are immersed into the salt to serve as the anode. A steel cylinder is immersed into the salt to serve as the cathode. During electrochemical transport, the spent fuel is electrochemically dissolved from the anode baskets with an amount of uranium depositing on the cathode to satisfy the charge balance. This process separates the uranium from the bulk of the fission products, the fuel jacket known as cladding, and the TRUs. Most of the fission products (alkali, alkaline earth, rare earths, and halides) and TRUs accumulate in the salt as metal chlorides because the thermodynamics of these elements are more stable as metal chlorides than that of $\mathrm{UCl}_{3}$.

The fuel processed in the electrorefiner was spent blanket from the Experimental Breeder Reactor II (EBR-II), a 63.5-MW(thermal) liquid metal-cooled fast breeder reactor that operated from 1964 to 1994. Blanket fuel, initially composed of depleted uranium $\left(99.8 \%{ }^{238} \mathrm{U}\right.$ in U) surrounded the EBR-II reactor core to absorb fast neutrons, which converted $\sim 1$ to 2 at. $\%$ of the ${ }^{238} \mathrm{U}$ to TRUs with some fission products. The EBR-II spent fuel inventory reduction, along with experiments performed during the demonstration of the electrometallurgical treatment, processed $2.4 \mathrm{t}$ of heavy metal from blanket fuel. These activities, carried out previously, allowed kilogram quantities of TRUs and rare earths to accumulate in the 
electrorefiner salt. Unless the TRU material is extracted, it will continue to accumulate until the salt, still containing large amounts of TRU material, is removed from the electrorefiner and converted into a ceramic waste form for disposal in the repository. The method currently available to extract kilogram quantities of plutonium and other TRUs from the electrorefiner at the Idaho National Laboratory (INL) is the liquid cadmium cathode (LCC). Earlier TRU recovery work proving the concept of electrochemical transport using liquid cathodes had been performed at the laboratory scale (gram quantities of TRU recovered) in Japan, ${ }^{2}$ in France, ${ }^{3}$ in Illinois ${ }^{4}$ (at the Argonne National Laboratory), and in Idaho ${ }^{5}$ (at the INL). This paper discusses TRU recovery experiments performed in an engineering-scale electrorefiner at the INL to collect kilogram quantities of uranium and plutonium into an LCC.

\section{EXPERIMENTAL}

The electrorefiner used for the TRU recovery experiments is a steel vessel $1 \mathrm{~m}$ in height with a 1-m inside diameter containing molten salt, primarily $\mathrm{LiCl}-\mathrm{KCl}$, maintained at $773 \mathrm{~K}$. Figure 1 is a schematic of the INL electrorefiner that processes EBR-II blanket fuel.

The anode basket (Fig. 2) used in each TRU recovery experiment is a steel vessel with perforated sides and bottom that can hold a maximum of $25 \mathrm{~kg}$ of cladding and heavy metal from EBR-II blanket fuel. The composition of EBR-II blanket fuel is shown in Table I. The cathode used in each experiment was a crucible made

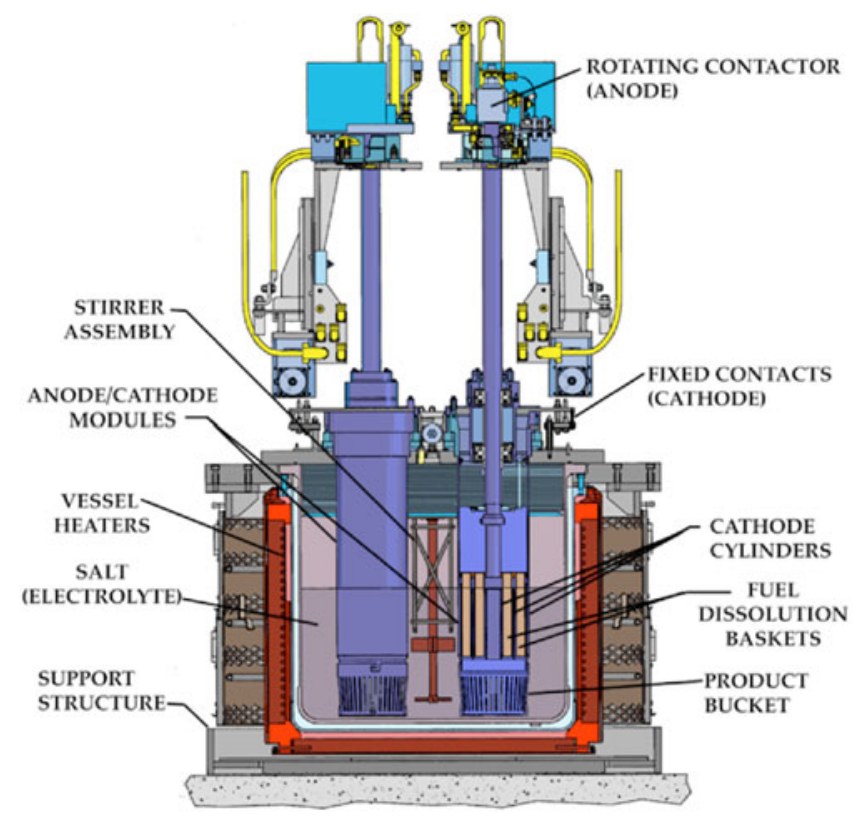

Fig. 1. Mark-V electrorefiner.

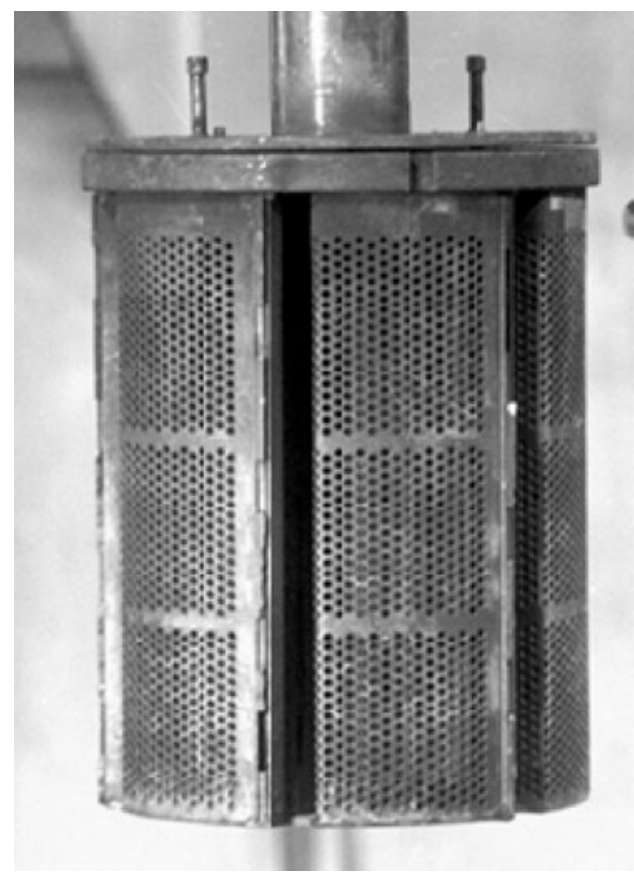

Fig. 2. Anode basket used in TRU recovery experiments.

TABLE I

Composition of EBR-II Blanket Fuel

\begin{tabular}{|l|c|c|c|}
\hline \multicolumn{1}{|c|}{ Nuclide } & Average & Maximum & Minimum \\
\hline${ }^{238} \mathrm{U}(\%)$ & 98.94 & 99.63 & 97.86 \\
${ }^{239} \mathrm{Pu}(\%)$ & 0.80 & 1.57 & 0.14 \\
${ }^{235} \mathrm{U}(\%)$ & 0.20 & 0.22 & 0.18 \\
$\mathrm{Nd}(\mathrm{ppm})$ & 92 & 246 & 8 \\
$\mathrm{Ce}(\mathrm{ppm})$ & 53 & 142 & 4 \\
$\mathrm{La}(\mathrm{ppm})$ & 29 & 77 & 2 \\
$\mathrm{Pr}(\mathrm{ppm})$ & 27 & 73 & 2 \\
${ }^{237} \mathrm{~Np}(\mathrm{ppm})$ & 11 & 22 & 1 \\
${ }^{241} \mathrm{Am}(\mathrm{ppb})$ & 776 & 8300 & 2 \\
\hline
\end{tabular}

from beryllium oxide containing $26 \mathrm{~kg}$ of cadmium. Figure 3 contains photographs of the LCC electrode assembly and a new cadmium ingot. The white sections of the assembly (crucible, crucible containment blocks, paddle, and upper portion of the electrode) are composed of beryllium oxide. The lower $1.3 \mathrm{~cm}$ of the electrode is metal, which conducts current to the liquid cadmium.

The role of the paddle in the LCC assembly was to push material depositing on the cadmium surface into the liquid cadmium. The paddle rotated and oscillated up and down during the experiments. To mitigate the displacement of cadmium from the crucible, the paddle operation was such that its "down" position was set at a specified distance above the cadmium surface. When a sufficient 


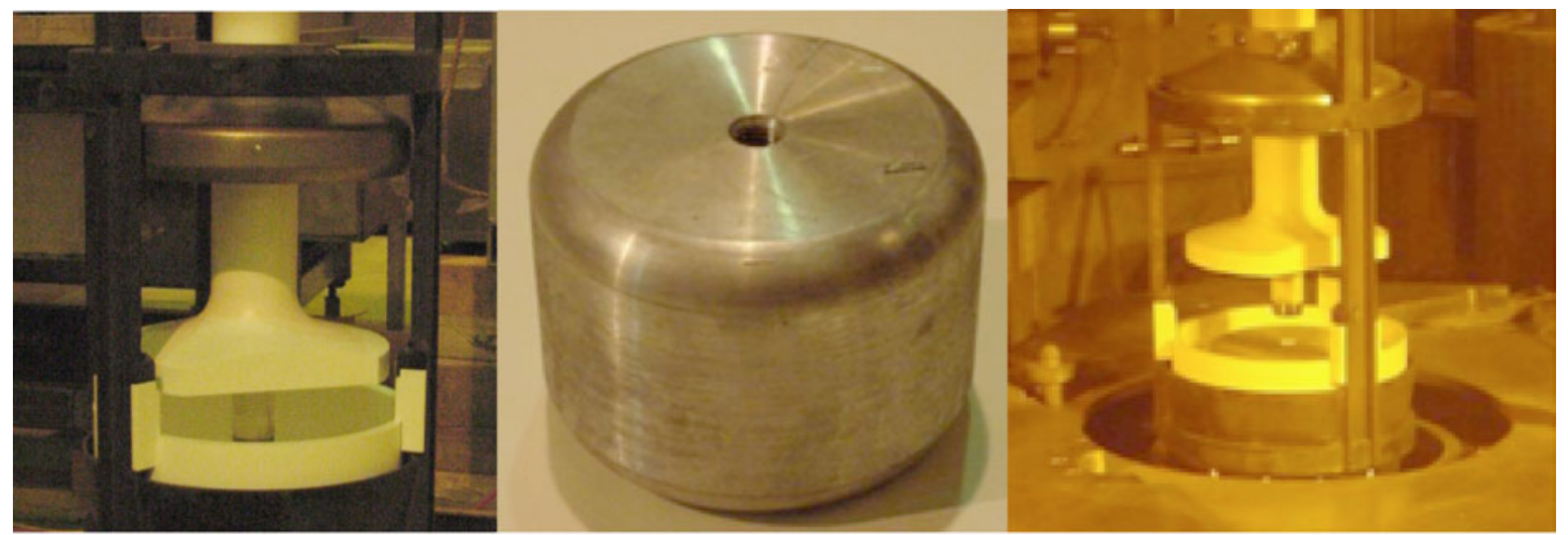

Fig. 3. Engineering-scale LCC.

amount of material deposited on the cadmium surface during electrotransport, the paddle on the down stokes would push the lower section of the deposit into the molten cadmium where it would dissolve into solution. The maximum "up" position during electrotransport was such that the metal portion of the electrode remained in the cadmium. As seen in the Fig. 3 photographs, the bottom surface of the paddle is not a complete cylinder or disk. Chords were removed from two sides of the paddle to allow salt displacement through the open chord area. To compensate for the change in cadmium level as uranium, TRUs, and rare earths were electrotransported to the cadmium, the paddle down position (position closest to the cadmium surface) was raised at the rate of $0.51 \mathrm{~mm}$ per 0.36 MC passed through the electrolyte. This was to keep the paddle from contacting the cadmium surface as much as possible.

For each of the three experiments a new cadmium ingot was used. To mitigate damage to the LCC crucible due to thermal shock if immersed quickly, ${ }^{6}$ it was held in the cover gas space above the molten salt for $4 \mathrm{~h}$ to reach thermal equilibrium and to allow the cadmium to melt. After the cadmium melted, the LCC crucible was lowered into the salt for $1 \mathrm{~h}$ to reach the $773 \mathrm{~K}$ electrolyte temperature. Table II contains the experimental conditions for the three LCC experiments.

The initial plutonium to uranium $(\mathrm{Pu}$ to $\mathrm{U})$ ratio in the electrolyte decreased from 10.8 to 3.67 with each experiment. This was due to the oxidation of uranium from the anode basket to the salt electrolyte while uranium, plutonium, minor actinides, and rare earths were reduced to the LCC. After each experiment, the LCC was removed from the electrorefiner. The LCC ingot was allowed to solidify before separating it from the ceramic crucible. A high-temperature vacuum furnace called a cathode processor was used to separate the cadmium and adhering salt from the U, TRU, and rare earths using high-temperature vacuum distillation. To meet the safe-
TABLE II

Transuranic Recovery Experiments: Experimental Conditions

\begin{tabular}{|l|c|c|c|}
\hline \multicolumn{1}{|c|}{ Input Parameters } & TRU \#1 & TRU \#2 & TRU \#3 \\
\hline Initial U concentration in salt (wt\%) & 0.27 & 0.53 & 0.69 \\
Initial Pu concentration in salt (wt\%) & 2.89 & 2.66 & 2.54 \\
Initial Pu to U ratio & 10.80 & 5.06 & 3.67 \\
Initial heavy metal in salt (wt\%) & 3.16 & 3.19 & 3.23 \\
Initial heavy metal in anode (kg) & 2.00 & 2.00 & 4.10 \\
Paddle down position (cm from Cd) & 0.51 & 0.25 & 0.25 \\
Paddle up position (cm from Cd) & 2.06 & 4.31 & 4.31 \\
Paddle travel (cm/s) & 3.1 & 4.1 & 4.1 \\
Salt stirrer (rpm) & 0 & 30 & 30 \\
Integrated current (MC) & 1.81 & 2.13 & 2.09 \\
Average current (A) & 20 & 20 & 20 \\
\hline
\end{tabular}

guards requirements for the Fuel Conditioning Facility, $\sim 12$ to $13 \mathrm{~kg}$ of depleted uranium was placed in the cathode processor along with the LCC ingot. The cathode processor ingot produced from the distillation was sent to another high-temperature furnace called the casting furnace, which is used to produce a homogeneous sample for analysis of the metal composition of the cathode processor ingot. By subtracting the depleted uranium added at the cathode processor, the amount of uranium transported from the anode basket to the LCC could be calculated.

\section{RESULTS}

The results of the three TRU recovery experiments are shown in Table III. All three experiments met the primary goal of recovering at least a kilogram of heavy 
TABLE III

Results of Transuranic Recovery Experiments

\begin{tabular}{|l|c|c|c|}
\hline \multicolumn{1}{|c|}{ Results } & TRU \#1 & TRU \#2 & TRU \#3 \\
\hline Heavy metal recovered (g) & 1365 & 1739 & 1313 \\
Pu in casting furnace ingot (g) & 1024 & 1080 & 492 \\
237 Np in casting furnace ingot (g) & 4.5 & 1.2 & 0.6 \\
U in salt at end of test (wt\%) & 0.47 & 0.74 & 0.83 \\
Pu in salt at end of test (wt\%) & 2.67 & 2.46 & 2.38 \\
MC of recovered metal & 1.65 & 2.11 & 1.59 \\
Integrated current (MC) & 1.81 & 2.13 & 2.09 \\
Transport efficiency (\%) & 91.5 & 99.2 & 76.1 \\
\hline
\end{tabular}

metal into the liquid cadmium, as seen in the first row. The second row shows that the first two TRU recovery experiments recovered a kilogram of plutonium from the electrorefiner salt. In a comparison of the three experiments in Table III, the second experiment had the best transport efficiency. Transport efficiency is defined as the Coulomb equivalent in recovered metal divided by the integrated current passed.

Figure 4 contains photographs of the crucibles after the three LCC experiments. The photographs show the formation of dendritic material exterior to the liquid cadmium in the first and third TRU recovery experiments. The second TRU recovery experiment had almost no dendritic material. Comparing the photographs in Fig. 4 to the results in Table III, the amount of dendritic material seen in each experiment appears to correlate with the transport efficiency. Future experiments are planned to reduce the formation of the dendritic material exterior to the cadmium surface. This reduction, based on the experimental results, should increase the transport efficiency.

From the three TRU recovery experiments, the low concentrations of rare earths and other actinides in the electrolyte and anode basket, and the barely detectable levels of rare earths in the LCC ingots, did not provide enough information to adequately determine distribution coefficients and separation factors. The objective here was to extract kilogram quantities of heavy metal from the electrorefiner electrolyte. Separation factors were determined using laboratory-scale equipment. Future work will investigate the transport of rare earths when their concentration in the electrolyte reaches significant levels.

In the design of the engineering-scale electrorefiner for TRU recovery, beryllium oxide $(\mathrm{BeO})$ was chosen as the crucible material because it is nonconducting and is nonreactive in a molten chloride salt. These properties allow for repeated use of the $\mathrm{BeO}$ crucible in TRU recovery operations. The TRU recovery experiments were successful using beryllium oxide ceramic crucibles. Unfortunately, when removing the cadmium ingot from the $\mathrm{BeO}$ crucible in two of the three experiments, the crucible was damaged beyond the point of reuse or repair. Even though $\mathrm{BeO}$ was chosen to provide a multiple-use crucible for TRU recovery, it ended up as a single-use crucible in the majority of TRU recovery experiments.

An alternative crucible material is aluminium oxide $\left(\mathrm{Al}_{2} \mathrm{O}_{3}\right)$, which is less expensive than $\mathrm{BeO} . \mathrm{Al}_{2} \mathrm{O}_{3}$, if used a limited number of times, is also nonconducting and inert to the molten salt. Repeated use of $\mathrm{Al}_{2} \mathrm{O}_{3}$ for electrotransport in a molten chloride salt causes it to become conductive and not suitable for electrotransport. But as a single-use crucible, aluminium oxide is a lessexpensive alternative to $\mathrm{BeO}$ for the TRU recovery experiments. Earlier experiments on the laboratory scale used aluminium oxide crucibles with success. Future experiments will study the use of aluminium oxide crucibles in TRU recovery experiments on the engineering scale.

\section{CONCLUSIONS}

All three engineering-scale TRU recovery experiments were successful with respect to electrotransporting

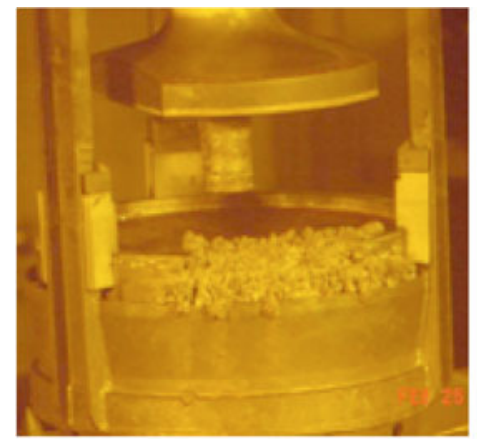

(a)

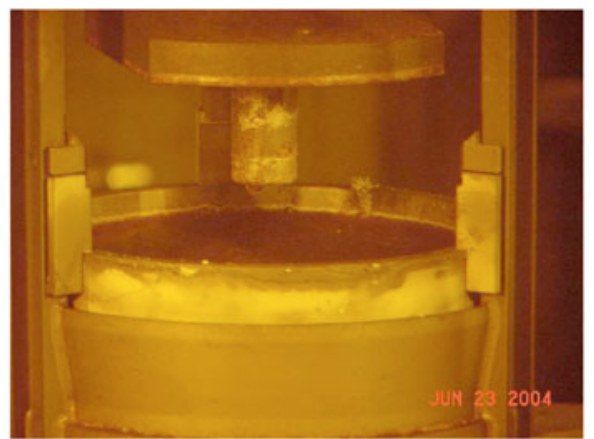

(b)

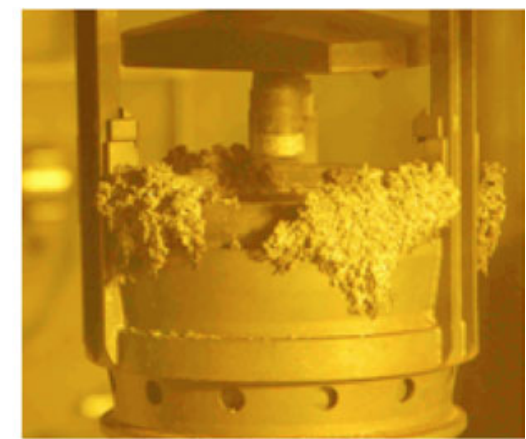

(c)

Fig. 4. Crucibles after (a) first, (b) second, and (c) third LCC experiments. 
transuranics from the electrorefiner to the LCC. The three TRU recovery experiments performed to date recovered kilogram quantities of uranium and TRUs. Over a kilogram of TRUs were recovered in the first two experiments, with almost $500 \mathrm{~g}$ of TRU recovered in the third experiment. The concentration of plutonium in the salt decreased with each experiment as the uranium concentration in the salt increased. This was an indication that, during electrotransport, uranium was being oxidized from the anode basket to the salt while plutonium was being reduced from the salt to the LCC. Even though the beryllium oxide crucibles were damaged when removing the cadmium ingot from the crucible, the experiments did succeed in extracting TRUs from the electrorefiner on an engineering scale.

Future LCC experiments will study the following:

1. TRU recovery using crucibles constructed of less expensive materials such as aluminium oxide

2. methods to reduce the formation of product external to the cadmium pool to improve the transport efficiency

3. TRU recovery with higher rare earth concentrations in the electrolyte.

\section{REFERENCES}

1. J. LAIDLER, "Development of Pyroprocessing Technology," Prog. Nucl. Energy, 31, 1/2, 131 (1997).

2. M. IIZUKA, K. UOZUMI, T. INOUE, T. IWAI, O. SHIRAI, and Y. ARAI, "Behavior of Plutonium and Americium at Liquid Cadmium Cathode in Molten LiCl-KCl Electrolyte," $J$. Nucl. Mater., 299, 1, 32 (Oct. 2001).

3. J. LACQUEMENT, A. LAPLACE, O. CONOCAR, S. BOURG, M. LECOMTE, B. BOULLIS, P. BROSSARD, D. WARIN, Z. TOMCZUK, and J. LAIDLER, "Assessment of Pyrochemical Processes at CEA: Objectives and Current Results," Global 2003, New Orleans, Louisiana, November 1620, 2003, American Nuclear Society (2003).

4. Z. TOMCZUK, J. P. ACKERMAN, R. D. WOLSON, and W. E. MILLER, "Uranium Transport to Solid Electrodes in Pyrochemical Reprocessing of Nuclear Fuel," J. Electrochem. Soc., 139, 12, 3523 (Dec. 1992).

5. S. X. LI, "Experimental Observations on the Roles of Cadmium Pool in MARK-IV Electrorefiner," Nucl. Technol., 162, 144 (2008).

6. C. W. SOLBRIG and D. VADEN, "Electrorefiner Liquid Cadmium Cathode Crucible Thermal Shock," Sep. Sci. Technol., 41, 10, 1985 (2006). 